\title{
SERRANO-DOLADER, D. (2019). FORMACIÓN DE PALABRAS Y ENSEÑANZA DEL ESPAÑOL LE/L2. LONDRES/NUEVA YORK: ROUTLEDGE. 350 PÁGINAS
}

\author{
Leticia González Corrales \\ Universidad Rey Juan Carlos \\ Departamento de Ciencias de la Educación, Lenguaje, Cultura y Artes, \\ Ciencias Histórico-Jurídicas y Humanísticas y Lenguas Modernas \\ leticia.gonzalez@urjc.es \\ https://orcid.org/0000-0001-7604-8535
}

\begin{abstract}
"Regala un pescado a un hombre y le darás alimento para un día, enséñale a pescar y lo alimentarás para el resto de su vida (Proverbio chino)" (p. 1). Formación de palabras $y$ enseñanza del español LE/L2 se abre con esta cita, cuya elección no es, en absoluto, arbitraria: David Serrano-Dolader establece un acertado paralelismo entre el proverbio y las consecuencias de la reflexión morfológica en el proceso de enseñanza y adquisición del vocabulario en el aula de ELE.

En las páginas preliminares se ocupa de especificar tanto los objetivos de la obra como sus potenciales destinatarios, los profesores de español como lengua extranjera, a quienes invita a continuar con su labor investigadora e introducir la morfología derivativa en sus programas. Seguidamente ofrece un breve resumen por capítulos de la obra, del que se trasluce una división entre el tratamiento específico de los mecanismos de formación de palabras en los últimos capítulos y la justificación de "la necesidad y la pertinencia de atender a la morfología léxica en el proceso de adquisición del vocabulario en segundas lenguas" (p. 2).

Partiendo de las teorías de la segmentación del léxico y de la composicionalidad del significado, Serrano-Dolader subraya los beneficios de la reflexión morfológica en el primer capítulo. Ante la escasa atención que ha recibido la morfología derivativa -a diferencia de la flexiva- en los modelos comunicativos que dominan la enseñanza de segundas lenguas, argumenta que su estudio no solo permite al estudiante "trascender la relación arbitraria de forma y significado que caracteriza a las palabras simples" (p. 14), sino que también favorece su autonomía. Se propone la primera batería de actividades con las que se promueve la reflexión en el aula y de las que surgen las primeras dificultades para la aplicación práctica de este proceso, como la falsa segmentación, además de la necesidad de la adaptación según los niveles.
\end{abstract}

Para citar esta reseña / To cite this book review: González Corrales, Leticia (2020). Reseña de Serrano-Dolader, D. (2019): Formación de palabras y enseñanza del español LE/L2. Londres/Nueva York: Routledge. 350 páginas. ELUA, 34: 233-236. https://doi.org/10.14198/ELUA2020.34.13

Enlace / Link: https://doi.org/10.14198/ELUA2020.34.13 
En el siguiente capítulo, profundiza en los beneficios del estudio de la morfología léxica en el proceso de enseñanza-aprendizaje del español desde una perspectiva metodológica. Sugiere dedicar especial atención a los morfemas derivativos, así como a las raíces, que permiten establecer relaciones entre miembros de una familia léxica, a fin de seguir la organización estructural del lexicón mental y coadyuvar, así, al aprendizaje. Asimismo, el conocimiento de las reglas de formación de palabras no solo es útil para las tareas de descodificación, sino que también contribuye a las de codificación, en la que se puede aplicar un componente lúdico con el propósito de estimular el empleo de las reglas. Sin embargo, aunque el juego es positivo a la hora de potenciar esa creatividad, la tarea del docente será la de adecuar la actividad al perfil de su alumnado (intereses, nivel de conocimiento, edad, etc.), animar a la participación y servir de guía ante el error.

En el tercer capítulo ("El vocabulario y las familias de palabras"), el autor aborda la cuestión del proceso de aprendizaje del léxico partiendo de la controvertida distinción entre la amplitud del vocabulario (breadth o size) y la profundidad del conocimiento de dicho vocabulario (depth o quality). Afirma que, si bien no es suficiente para completar el proceso, el tratamiento de los recursos de formación de palabras en el aula favorece el (re)conocimiento del léxico. A fin de lograr la consecución total de este objetivo, algunos autores han señalado seis recursos entre los que se encuentra la toma de conciencia morfológica.

Por otro lado, para establecer un vínculo estrecho entre el proceso de aprendizaje y los mecanismos de formación de palabras, Serrano-Dolader propone el empleo de redes asociativas de acuerdo con los beneficios que estas reportan tanto en la adquisición como en el afianzamiento del léxico; en concreto, las familias morfológicas de palabras, que define como "un conjunto formado por una palabra base y todas sus formas derivadas [...]" (p. 61). No obstante, reconoce las limitaciones de la aplicación de esta red asociativa en el aula, ya que su configuración no está sujeta a un criterio unánime, a lo que se suma la falta de datos empíricos que corroboren la relación entre conocer la estructura morfológica de una pieza léxica y la capacidad de poder establecer vínculos con otras. A modo de conclusión se ofrecen pautas metodológicas basadas en la transversalidad de la enseñanza-aprendizaje del léxico: el tratamiento de una nueva unidad irá acompañada de la reaparición -y posterior vinculación- de otras ya conocidas con las que presenta paralelismos en su estructura formal.

El cuarto capítulo lo vertebra el concepto de productividad, donde se especifica qué procesos lexicogenéticos deben recibir mayor atención en el aula de ELE. Tras presentar tres factores que se subsumen en la productividad, a saber, la disponibilidad, la rentabilidad y la regularidad, el autor concluye que, en el ámbito de la enseñanza de segundas lenguas, solo son determinantes los dos últimos, ya que de ellos depende la sistematización del aprendizaje de las reglas de formación de palabras. De hecho, en casos de irregularidad o de recursos escasamente productivos, recomienda un tratamiento similar al de las unidades simples.

Tras varias páginas de justificación y presentación, en el quinto capítulo se concreta la guía para la reflexión morfológica en la enseñanza de segundas lenguas dividida en cuatro fases: el reconocimiento de la forma, la identificación y el posterior análisis de sus constituyentes, la asignación del significado y, finalmente, la producción. Sin embargo, el autor advierte de que su propuesta requiere una ulterior adaptación en función del grupo al que se destine, aparte de un marco comunicativo en el que insertarse.

Tanto el reconocimiento como la identificación y análisis de los constituyentes se tratan de manera conjunta y retoman algunas cuestiones tratadas con anterioridad, como los procesos 
de asociación morfológica que dan lugar a las familias léxicas y el tratamiento de los errores en el reconocimiento.

Con respecto a la etapa de asignación del significado, se señalan una pluralidad de casos a los que el docente deberá atender de manera individualizada: las palabras complejas con significado composicional frente a las que presentan un significado lexicalizado, los afijos polisémicos, los afijos sinonímicos y los errores derivados de falsas segmentaciones, que se deberán tratar en la fase anterior. Serrano-Dolader presenta una serie de actividades para cada una de estas situaciones con distintos objetivos: explotar la operatividad de los procesos regulares de formación de palabras en aquellas cuyo significado es composicional y transparente, o bien, concienciar al estudiante del resto de casos problemáticos para minimizar el número de errores.

Por último, la etapa de producción requiere una instrucción en las restricciones combinatorias del español, cuyo aprendizaje supone un desafío para el estudiante, quien tiende a la sobregeneralización -o hipergeneralización - en esta fase creativa. Los resultados de esta tendencia pueden ser inaceptables bien por violar la norma, o bien por ser formas inexistentes en la lengua, aunque posibles. Las actividades propuestas responden a esta distinción y están orientadas a los distintos niveles de la lengua: fónico, morfológico, sintáctico y semántico.

En los cuatro capítulos restantes se atiende a los procesos morfológicos más productivos del español de manera individualizada: la prefijación (capítulo 6), la sufijación (capítulos 7 y 8) y la composición (capítulo 9). En ellos, los modelos de actividades para la práctica en el aula de ELE ocupan un lugar prominente en detrimento del aparato teórico y responden a los objetivos específicos de cada uno de los capítulos. Dada la variedad de la oferta, los ejercicios no solo sirven de apoyo para ejercitar al alumnado en los casos más regulares, sino que también inciden en aquellas cuestiones problemáticas que deberán ser presentadas en el aula a fin de reducir los errores de identificación de morfemas y de producción léxica.

Debido a la regularidad y la transparencia semántica de las unidades formadas por prefijación, resulta conveniente la aproximación a este recurso morfológico desde el punto de vista del significado. Así, partiendo de la Nueva gramática de la lengua española (2009) de la Real Academia Española, el autor establece en el sexto capítulo una organización de los prefijos en función de su significado: los prefijos ubicativos, en los que engloba los llamados prefijos temporales y espaciales, los gradativos-apreciativos -estrechamente vinculados con los anteriores-, los negativos, cuyos matices semánticos se simplifican en aras del didacticismo, y los cuantificativos, que reciben un tratamiento más complejo que en la obra académica con el fin de contribuir a la coherencia.

Las características de la sufijación, por el contrario, no favorecen la sistematización con fines didácticos: la alomorfia, los casos de polisemia y sinonimia entre sufijos, las restricciones combinatorias y los falsos cognados representan un escollo en el proceso. Pese a ello, el capítulo 7 ofrece una propuesta para la enseñanza de la sufijación no apreciativa basada en las dificultades que presentan los alumnos anglófonos en lo que respecta a la morfología derivativa española. "Puesto que en numerosas ocasiones los alumnos de niveles iniciales de ELE pueden tener conocimiento de inglés, parece que la selección de esta lengua como punto de referencia a la hora de pautar tareas derivativas podría estar justificada metodológicamente" (pág. 194). El capítulo se estructura, por tanto, en cuatro subapartados que responden a las categorías resultantes del proceso de sufijación, a saber, la derivación nominal, la adjetival, la adverbial y la verbal, en los que también se procura atender al plano semántico. 
La sufijación apreciativa recibe tratamiento aparte (capítulo 8) como consecuencia de su componente pragmático y subjetivo. Aunque presenta brevemente otros sufijos susceptibles de recibir una carga apreciativa, Serrano-Dolader centra su atención en los casos más representativos de este grupo, a saber, los diminutivos, los aumentativos y despectivos. A la dificultad que entraña la (des)codificación de los matices que caracterizan a estas formaciones, se suman las variables de tipo geográfico y sociolingüístico a las que está sujeto su empleo, razón por la que se han abordado tradicionalmente en los niveles más avanzados. En esta ocasión, no se aporta un método concreto para su estudio, sino que se plantean una serie de actividades destinadas a arrojar luz sobre los interfijos, las formas lexicalizadas y los posibles valores que puede atribuir la sufijación apreciativa.

La obra se cierra con un breve capítulo dedicado a la composición, bajo la que subsume los compuestos unidos gráficamente, los compuestos sintagmáticos y la composición con temas cultos. La adaptación didáctica de este recurso pretende explotar la capacidad que demuestra el estudiante en la identificación de los constituyentes que conforman los compuestos presentando este mecanismo a través de las combinaciones categoriales más frecuentes en español; sin embargo, las actividades están enfocadas a la resolución de conflictos en el plano semántico, ya que, con frecuencia, el significado de las formaciones no es deducible a partir de los procedimientos de segmentación regulares.

Formación de palabras y enseñanza del español LE/L2 aporta las claves necesarias para trasladar la morfología derivativa a la enseñanza del español como lengua extranjera. Su autor cumple sobradamente los objetivos establecidos al comienzo de la obra sacrificando el rigor científico en virtud de la claridad expositiva: no solo aduce argumentos sólidos a favor de la incorporación de esta parcela de la morfología española en el ámbito de la enseñanza de segundas lenguas, sino que también orienta al lector en la elaboración de sus materiales didácticos mediante una serie de propuestas específicas para los tres procesos morfológicos de los que se ocupa, cuyo valor se incrementa con las actividades que las acompañan.

Pese a que los modelos para la práctica en el aula no son definitivos como consecuencia de su carácter descontextualizado, sirven de guía en el proceso de adaptación didáctica que queda supeditado al criterio del profesor. De su competencia depende, por tanto, la selección de los contenidos, su contextualización, así como la adecuación a las necesidades y los intereses del alumnado, para lo cual será preciso que su formación en la materia sea lo más completa posible. Ello explica que, en ocasiones, los contenidos de la obra excedan los límites del didactismo y aborden cuestiones que, a pesar de su dudosa aplicación en el aula, son imprescindibles para una comprensión cabal del fenómeno.

En definitiva, Formación de palabras y enseñanza del español LE/L2 es una obra de inestimable ayuda para los docentes de español como segunda lengua con la que se pretende instruir en la reflexión morfológica y colaborar, así, en los esfuerzos destinados a la mejora de los métodos de enseñanza y aprendizaje del vocabulario en el ámbito de lenguas extranjeras. 